\section{A polissemia do verbo dar: uma análise funcionalista}

The polysemy of the verb to give: a functionalist analysis

Luana Carvalho COELHO (UESB) luanacoelho90@hotmail.com Valéria Viana SOUSA (UESB) valeriavianasousa@gmail.com
COELHO, Luana Carvalho; SOUSA, Valéria Viana. A polissemia do verbo dar: uma análise funcionalista.

Entrepalavras, Fortaleza, v. 7, p. 7492, ago./dez. 2017.

Resumo: A língua como objeto social é passível a mudanças. Assim, inovações surgem constantemente, e novos conceitos, significados vão se formando. A partir dessa perspectiva, objetivamos com esse estudo refletir sobre a natureza polissêmica do verbo dar no português brasileiro à luz do Funcionalismo norte-americano a fim de investigar as alterações sofridas na forma e na função por esse verbo. As amostras analisadas nesta pesquisa foram extraídas do Corpus do Português Popular de Vitória da Conquista (Corpus PPVC) e do Corpus do Português Culto de Vitória da Conquista (Corpus PCVC), organizados pelo Grupo de Pesquisa em Linguística Histórica e em Sociofuncionalismo. Para análise, descrevemos as extensões de sentido do verbo dar e, por meio dos sentidos encontrados nos corpora, analisamos o nível de transitividade das ocorrências com o verbo dar de acordo com os parâmetros propostos por Hopper e Thompson (1980). Nesse estudo, constatamos que o processo de gramaticalização é o responsável pela capacidade categorial desse verbo. Além disso, verificamos que a potencialidade e produtividade do verbo dar contribuem para o seu comportamento polissêmico.

Palavras-chave: Verbo dar. Funcionalismo. Transitividade. 
Abstract: The language as a social object is subject to change. Thereby, innovations are constantly emerging and new concepts, meanings are formed. From this perspective, it is intended with this study reflect on the polysemic nature of the verb give in Brazilian Portuguese in the light of the American functionalism in order to investigate the changes suffered in the form and function of this verb. The samples analyzed in this study were taken from the Corpus of Vitória da Conquista's Popular Portuguese (VCPP) and Corpus of Vitória da Conquista's Formal Portuguese (VCFP), organized by the Historical Linguistics and Sociofuncionalismo. For analysis, we describe the extensions of the verb meanings and through the senses found in the corpora, we analyzed the transitivity level of occurrences of the verb 'give' in accordance with the parameters proposed by Hopper and Thompson (1980). In this study we found that the grammaticalization process is responsible for the categorical capacity of this verb. Moreover, we found that the potentiality and productivity of the verb to contribute to its polysemic behavior.

Keywords: Verb 'to give'. Functionalism. Transitivity.

\section{Introdução}

Ao considerar que o processo de variação na linguagem está relacionado a fatores sociais, percebemos que, naturalmente, a língua em uso tem-se afastado das normas prescritas pela Tradição Gramatical. Inovações surgem constantemente, e novos conceitos, significados, palavras vão se formando. Nesse processo de variação/mudança linguística, notamos que os fenômenos da linguagem são muito mais complexos do que as regras estabelecidas e, assim, em uma perspectiva funcionalista, podemos afirmar que velhas formas passam a ocupar novos sentidos diante de uma necessidade expressiva na interlocução.

O verbo dar, em questão, apresenta, em diversos contextos de fala, um processo de ressemantização que contribui para o surgimento de novas categorias gramaticais com as quais este verbo se relaciona, configurando-se, dessa maneira, a sua polifuncionalidade. Conforme Salomão (1990), o verbo dar tem um sentido básico capaz de irradiar muitos outros. Sendo assim, por notar nas diversas mudanças operadas pelo verbo dar, que se desloca do seu sentido canônico ${ }^{1}$ para outros significados, acreditamos que são necessários, portanto, estudos que contribuam para a compreensão de que os sentidos não se limitam a uma acepção conceitual. E essa é a nossa intenção no presente artigo.

Ferreira (2010) apresenta o sentido básico do verbo dar, que seria doar, presentear, ceder. A interpretação das construções com o

\footnotetext{
${ }^{1}$ O modelo canônico do verbo dar é representado por uma oração com um sujeito agentivo que transfere, intencionalmente, um objeto concreto a um destinatário, como ocorre em Lucas deu uma bicicleta para o seu filho, no qual temos um objeto concreto, uma bicicleta, que é transferida das mãos de Lucas para o filho.
} 
v. 7 (2)

74-92

ago/dez 2017

verbo, portanto, remete à ideia de transferência, isto é, o responsável pela ação desloca algo para o paciente da ação. Dessa forma, o verbo dar é transitivo por excelência. Entretanto, partimos do pressuposto de que cada expressão adquire nuances de sentidos diferentes. O falante escolhe, geralmente, a estrutura com verbo dar por favorecer significados especiais aos enunciados, surgindo, assim, maiores efeitos comunicativos. A título de exemplo, observamos que o dar é normalmente usado no lugar de um verbo pleno correspondente, isto é, como verbo suporte, como ocorre em dar uma volta no lugar de passear.

Por uma perspectiva funcionalista, podemos afirmar que o verbo dar deslocou-se da função canônica de verbo pleno, passando por transferência de algo mais concreto para mais abstrato. Atentos a esse comportamento do verbo dar, objetivamos, com este estudo, guiados, sobretudo, pelo Funcionalismo, investigar a multiplicidade de sentidos do verbo dar, na qual o sentido etimológico é ampliado, e outros significados passam a ser atribuídos a esse verbo, para refletir se tais estruturas analisadas são portadoras de significado (+ lexical) ou representam ferramentas de construção de sentido (+ gramatical). Para isso, apresentamos as extensões de sentido do verbo dar encontradas nos corpora e analisamos o nível de transitividade das ocorrências de acordo com os parâmetros propostos por Hopper e Thompson (1980). Inicialmente, tratamos dos pressupostos do Funcionalismo, com o propósito de situar a ancoragem teórica eleita por nós para analisar o fenômeno em estudo. Em seguida, após a descrição da metodologia empregada para a realização desta pesquisa, apresentamos as discussões e resultados da análise.

\section{Funcionalismo e o processo de gramaticalização}

Para começarmos a discussão, optamos por, inicialmente, tratar dos pressupostos teóricos do Funcionalismo norteamericano, focalizando, principalmente, nesta teoria, o processo de gramaticalização e apresentar aspectos que nortearam a nossa análise, a saber: o princípio da iconicidade, a dicotomia diacronia e sincronia. Além disso, iniciamos o diálogo com o nosso objeto de estudo, o verbo dar.

No século XX, o aparecimento do Cours de Linguistique Générale, de Ferdinand de Saussure, influenciou os estudos linguísticos a ter uma nova orientação com relação ao enfoque e ao objeto de estudo da língua. A nova tendência, que se desenvolveu a partir da publicação do Cours, 
teve sua primeira expressão nos trabalhos do Círculo Linguístico de Praga, a partir de 1928. A corrente funcionalista surgiu dos trabalhos dos membros do Círculo, que viram, para além do conceito saussuriano, a função como um elemento essencial à linguagem.

As pesquisas sobre mudança linguística ganharam força nos Estados Unidos, a partir da década de 1970, quando os estudos se voltaram à observação da língua por meio do contexto linguístico. Com o surgimento da linguística funcional, no Estruturalismo, passa a haver espaço, também, para uma concepção de língua mais dinâmica,

[...] segundo a qual a linguagem funciona como um elemento criador de significação dos diferentes contextos de uso. Assim, passa-se a observar não apenas a palavra ou a frase, mas o texto, o qual reflete um conjunto complexo de atividades comunicativas (MARTELOTTA, 2008, p. 77).

A partir do estudo da linguística funcional, a língua passa a ser observada, portanto, como reflexo do comportamento dos falantes em situação real de comunicação. Os funcionalistas, então, consideram a função da forma linguística na comunicação, visto que a língua está sujeita às pressões advindas do uso, mas sem perder de vista a estrutura que advém da comunicação, pois a regularidade da estrutura é que possibilita fazer generalizações. Além disso, para os funcionalistas, a gramática não é concebida por fatores cognitivos inatos, como defendem os gerativistas, mas por padrões do uso. Assim, surge o conceito de gramática emergente². Nas palavras de Martelotta, Votre e Cezario (1996),

a gramaticalização é uma manifestação do aspecto não estático da gramática, uma vez que ela demonstra que as línguas estão em constante mudança em consequência de uma incessante busca de novas expressões e que, portanto, nunca estão definitivamente estruturadas. (MARTELOTTA; VOTRE; CEZARIO, 1996, não paginado).

Algumas noções foram adotadas pelos funcionalistas, entre elas, podemos citar a iconicidade. A noção de iconicidade se baseia na ideia de que existe uma relação motivada entre os elementos da linguagem e os seus sentidos. Assim, a compreensão apresentada na teoria é de que o falante utilize material já existente na língua para formar novas palavras. Dessa forma, palavras velhas ressurgem com novas funções na língua em uso diante da necessidade de uma maior expressividade.

\footnotetext{
${ }^{2}$ Paul Hopper defendeu, em 1987, a concepção de gramática como emergente, pois, para ele, a gramática é um fenômeno social que apreende o caráter provisório da língua. Dessa forma, o processo de formação nunca está acabado.
} 


\section{v. 7 (2)}

74-92

ago/dez 2017

Conforme Martelotta e Areas (2003), no campo da sintaxe, por exemplo, os funcionalistas consideram a motivação icônica quando há narração de sequências de ações, como cheguei em casa, tomei um banho e fui dormir. Explicam que, neste tipo, a ordem das cláusulas não é realizada de forma aleatória, mas de acordo com a ordem em que elas ocorrem. A essas tendências que refletem algum tipo de motivação, os funcionalistas chamam iconicidade.

A dicotomia sincronia/diacronia é outro dogma ${ }^{3}$ Estruturalista que foi revisto pelo Funcionalismo. Para Saussure, a análise sincrônica e a análise diacrônica devem ser compreendidas como dois eixos separados que se restringem a seu domínio específico. Porém, nas pesquisas em gramaticalização, tem sido demonstrado que os fenômenos linguísticos podem ser estudados em sua trajetória ao longo do tempo, assim como podem manter, ao longo da trajetória da língua, um conjunto de sentidos concorrentes. Optamos, então, no Funcionalismo, por uma análise de cunho pancrônico, compreendendo que, observando as duas perspectivas, o estudo tende atender melhor os nossos objetivos. $\mathrm{O}$ verbo dar, por exemplo, teve o seu sentido de transferência ampliado ao longo do tempo, passando a significar produzir, como em: o pé de manga dá frutos; ensinar, como em: o professor dá aula; e até o sentido de causa, como em: a espera me deu o nervoso.

As extensões de sentido do verbo dar, como expostas, coocorrem com a sua função semântica básica de transferência. Por esse motivo, os funcionalistas observam a mudança a partir de um ponto de vista pancrônico, sem estabelecer, assim, prioridades em uma ou em outra perspectiva, mas, antes, compreendendo na função das perspectivas uma ampliação do olhar sobre o fenômeno estudado.

Para discorrer sobre o uso cotidiano da linguagem, é importante, também, lançar mão de duas abordagens da Linguística Cognitiva, as quais são: a metáfora e a metonímia. Ferrari (2016) defende que a metáfora é um mecanismo que envolve a conceptualização de um domínio de experiência em termos de outro. Dessa forma, um conceito formulado com base em propriedades concretas da experiência pode ser projetado para um domínio mais abstrato. Em dar um beijo, por exemplo, existe uma transferência metafórica, pois o verbo dar tem o seu significado expandido para transferir metaforicamente um beijo.

3 Segundo Givón (1995), há três dogmas centrais da linguística estrutural: a arbitrariedade do signo linguístico, a distinção entre langue e parole e a divisão rígida entre sincronia e diacronia. 
Assim como a metáfora, a metonímia também é essencial para o estudo da mudança semântica. Para Lakoff e Johnson (2002), a metonímia possui uma função referencial que admite usar uma entidade em substituição à outra, por exemplo, é comum ouvir "o Aurélio", isto é, o dicionário Aurélio, para se referir à obra. No entanto, a projeção metonímica, diferentemente da metáfora, envolve apenas um domínio. As duas abordagens, então, correspondem a processos de extensão de significados, fundamental para a cognição humana.

Com a intenção de evidenciar a correlação entre língua e funcionamento, ressurgiu uma vertente nos estudos funcionalistas sobre mudança linguística: a gramaticalização. Segundo Neves (2006), a gramaticalização é

um processo que tem encontrado abrigo privilegiado no funcionalismo [...] porque reflete a relação entre o sistema gramatical e o funcionamento discursivo, ou seja, porque se aplica pela interação entre motivações internas ao sistema e as motivações externas a ele (NEVES, 2006, p. 20).

Na verdade, conforme Neves (1996), os estudos acerca do processo de gramaticalização tiveram início na China, no século $\mathrm{X}$, mas foi no século XX, com Meillet (1965), que os estudos foram definidos pela primeira vez. O linguista conceituou gramaticalização como a atribuição de um caráter gramatical a uma palavra anteriormente autônoma.

Esse processo não ocorre repentinamente, mas, de forma gradual. A cada etapa, de maneira lenta, novas funções vão surgindo para determinada forma, por isso, muitas vezes, os falantes não percebem as mudanças na língua. No entanto, há um fator imprescindível para que isso ocorra: a frequência. De acordo com Bybee (2016), à medida que uma nova construção se expande, o seu significado também se generaliza. O uso frequente, portanto, segundo Bybee (2016), enfraquece o significado de uma construção em gramaticalização. A construção, então, pode aplicar-se a mais casos, em diferentes contextos de uso.

A gramaticalização, do ponto de vista diacrônico, é tipicamente unidirecional, e as transformações caminham do discurso para a gramática. A ideia de linearidade do processo de gramaticalização é defendida por Hopper e Traugott (1993), mostrando que esse processo se desenvolve sempre da esquerda para direita, sem a possibilidade do caminho inverso. No entanto, esse conceito vem sendo revisto por muitos funcionalistas. O verbo dar, por exemplo, já era empregado como expressões cristalizadas e como verbo suporte no português arcaico. 
v. 7 (2)

74-92

ago/dez 2017

As construções gramaticalizadas já eram utilizadas naquela época. Nesse sentido, esse fenômeno pode ser pensado não apenas no eixo da unidirecionalidade.

Para verificar mudanças em um item lexical para gramatical ou menos gramatical para mais gramatical, por exemplo, é possível identificar estágios na gramaticalização. Heine et alii (1991) defendem a ideia de que a gramaticalização ocorre em um processo que provoca o deslizamento de um sentido concreto para abstrato, ou seja, ela se estabelece numa escala crescente de abstraticidade. Para Martelotta, Votre e Cezário (1996), a gramaticalização envolve quatro diferentes níveis: no cognitivo, por meio de processo de mudança metafórica, elementos passam de concreto para abstrato ou do léxico para gramática; no nível pragmático, o falante utiliza conceitos mais concretos e mais conhecidos de forma genérica para expressar ideias novas como o intuito de facilitar a comunicação; a semântica, que envolve o conhecimento dos interlocutores do significado prototípico das palavras, senão, o sentido novo pode não ser entendido; e o nível sintático, responsável pelo caminho que a mudança seguirá.

Outro pressuposto adotado pelo Funcionalismo é a transitividade, noção importante para determinar a prototipia de um verbo. O verbo dar, por exemplo, para ser considerado em seu sentido canônico, precisa ter o sentido de transferência. Os funcionalistas norteamericanos, a exemplo de Hopper e Thompson (1980), fornecem uma análise da questão da transitividade em um complexo de dez parâmetros sintáticosemânticos. Embora independentes, esses traços funcionam juntos na língua para determinar a transitividade de uma oração. São eles: (1) participantes: para ocorrer a transferência é preciso que dois ou mais participantes estejam envolvidos; (2) cinese: estados não podem ser transferidos; (3) aspecto: uma ação concluída pode possuir um grau maior de transferência; (4) pontualidade: ações que são contínuas possuem um grau menor de transitividade, diferente das ações com início e fim; (5) intencionalidade: o efeito sobre o paciente é mais visível quando a ação é proposital; (6) polaridade: orações afirmativas podem ser transferidas, já as negativas, não; (7) modalidade: uma ação hipotética é menos eficaz do que uma ação que realmente ocorreu; (8) agentividade: participantes com alta agentividade podem realizar a transferência; (9) afetamento: o grau de transferência da ação pode ser maior ou menor dependendo do quanto o paciente é afetado; (10) individuação: o grau de transitividade irá depender do referente dos 
substantivos. Portanto, cada parte focaliza uma faceta da oração para identificar a transferência, abordagem bastante diferente da realizada na gramática tradicional, na qual apenas o verbo é responsabilizado pelo processo de transmitir sentido a outros elementos.

Com relação à abstratização, podemos constatar que o verbo dar possui, inicialmente, um sentido mais concreto de doação, de transferência, de cessão de algo concreto, como dar um presente, e adquire o traço mais abstrato em construções como dar informação, já que o que será transferido não é um objeto concreto. O dar é usado, então, como suporte ao predicador, e essa escolha reflete a busca por sentidos particulares, o que contribui para os novos sentidos atribuídos ao verbo, conforme os níveis previstos por Martelotta, Votre e Cezário (1996).

Como se vê, fica claro, então, que o essencial em um estudo funcionalista é verificar como acontece a interação em uma língua, reconhecendo que os itens linguísticos estão em constante reformulação por motivações internas e externas ao sistema linguístico.

\section{Metodologia e corpus}

As amostras analisadas nesta pesquisa foram extraídas do Corpus do Português Popular de Vitória da Conquista (Corpus PPVC) e do Corpus do Português Culto de Vitória da Conquista (Corpus PCVC), organizados pelo Grupo de Pesquisa em Linguística Histórica e em Sociofuncionalismo - CNPq. Tais corpora, de responsabilidade da pesquisadora Dra Valéria Viana Sousa, com cadastro no Certificado de apresentação para Apreciação Ética (CAAE), número 34221214.9.0000.00552, fazem parte do Projeto de Estudos de Fenômenos Linguísticos na Perspectiva Sociofuncionalista a partir da descrição e análise de corpus da comunidade de fala de Vitória da Conquista. Foram selecionadas, aleatoriamente, 24 (vinte e quatro) entrevistas, com 12 (doze) informantes pertencentes a cada corpus 4 e, nestas, foram retiradas as ocorrências do verbo dar para descrição e análise. Todos os informantes, falantes nativos do português brasileiro, naturais da cidade de Vitória da Conquista, foram estratificados como mostra o quadro abaixo:

4 Vamos nos referir aos corpora utilizando a seguinte legenda: PPVC (Português Popular da cidade de Vitória da Conquista - informante com até cinco anos de escolaridade); PCVC (Português Culto de Vitória da Conquista - informante com mais de onze anos de escolaridade); I (faixa I: 15 a 34 anos); II (faixa II: 35 a 49 anos); III (faixa III: 50 anos ou mais); F (sexo feminino); M (sexo masculino). 
v. 7 (2)

74-92

ago/dez 2017

Quadro 1 - Informantes dos corpora do Português Popular e do Português Culto

\begin{tabular}{|c|c|c|c|c|c|}
\hline \multicolumn{3}{|c|}{ Português Popular } & \multicolumn{3}{c|}{ Português Culto } \\
\hline Informante & Sexo & Idade & Informante & Sexo & Idade \\
\hline GNB & Feminino & 24 anos & LCS & Feminino & 20 anos \\
\hline CDS & Feminino & 31 anos & CBS & Feminino & 21 anos \\
\hline LBR & Masculino & 17 anos & FSLB & Masculino & 19 anos \\
\hline MSS & Masculino & 26 anos & JLS & Masculino & 21 anos \\
\hline ESP & Feminino & 38 anos & ASA & Feminino & 39 anos \\
\hline AAB & Feminino & 38 anos & ACMG & Feminino & 42 anos \\
\hline SAA & Masculino & 37 anos & HFDS & Masculino & 36 anos \\
\hline WSO & Masculino & 41 anos & RFV & Masculino & 37 anos \\
\hline MJPS & Feminino & 52 anos & JVB & Feminino & 54 anos \\
\hline ELC & Feminino & 96 anos & AIRM & Feminino & 60 anos \\
\hline EJR & Masculino & 83 anos & PARC & Masculino & 50 anos \\
\hline EFO & Masculino & 72 anos & DAO & Masculino & 51 anos \\
\hline
\end{tabular}

Com base nas entrevistas extraídas dos corpora e de acordo com os diversos sentidos atribuídos ao verbo dar no dicionário Ferreira (2010), encontramos oito extensões de sentido com o dar, a saber: fornecer; ensinar; bater; produzir; causar; combinar; soar e a extensão semântica possibilidade. Após essa seleção, analisamos o nível de transitividade de cada sentido, pois, quanto menor o nível de transitividade, maior o processo de gramaticalização do verbo. Para atender a esse propósito, utilizamos os estudos de Hopper e Thompson (1980), Maciel (2005) e Esteves (2008).

\section{Múltiplos sentidos do verbo dar}

São muitas as mudanças operadas pelo verbo dar, quando ele se junta a um nome ou a outro verbo, visto que, além de seu valor pleno de transferir, ceder alguma coisa, ocorrem variações do seu valor semântico básico. Nessa perspectiva, compreendemos que esse item seja polissêmico, pois o dar pode possuir múltiplos sentidos. Por esse motivo, buscamos nos corpora os sentidos do verbo dar, são eles: 
Tabela 1 - Extensões de sentido do verbo dar

\begin{tabular}{l|c|c|c}
\hline Múltiplos sentidos & Corpus Português Popular & Corpus Português Culto & Total \\
\hline Fornecer & 14 & 10 & 24 \\
\hline Ensinar & 2 & 11 & 13 \\
\hline Bater & 1 & 2 & 3 \\
\hline Produzir/gerar & 1 & 4 & 5 \\
\hline Causar & 9 & 5 & 14 \\
\hline Combinar/entender & 4 & 3 & 7 \\
\hline Soar & 2 & 1 & 3 \\
\hline Possibilidade & 19 & 20 & 39 \\
\hline
\end{tabular}

Para o verbo dar ser considerado em seu sentido canônico, é necessário que algo seja transferido para alguém. Deve haver, portanto, um agente que transfere um objeto concreto para um destinatário, isto é, $\left[\mathrm{X}_{\text {(agente) }}+\mathrm{DAR}_{\text {(objeto concreto) }}+\mathrm{Y}_{\text {(destinatário) }}\right]$. Percebemos, no enunciado a pastoral carcerária deve dá atenção pros presidiários, é que nem sempre o objeto transferido é real5. A construção pode ter um sentido metafórico, assim, o dar pode expressar a transferência de informação, conceito, valor ou alguma ideia abstrata. Nesse viés, podemos ordenar os diversos sentidos encontrados do dar por grau de afastamento do seu sentido básico, isto é, o grau de transitividade da construção. Para tanto, utilizamos como critério quatro parâmetros propostos por Hopper e Thompson (1980), são eles: participantes, aspecto, intencionalidade e afetamento. Esses parâmetros já são suficientes para determinar o grau de transitividade do verbo. Podemos começar, então, pelo sentido fornecer:

(1) A gente se conheceu, porque a gente, aveiz nas festas, assim, aveiz a gente se encontrava, uma pessoa dava informação pra gente e aí não tinha pai, mas tinha tio, juntava mais os pais e falava qualquer informação, no outro, e por aí a gente casava, né. (EJR Corpus PPVC)

(2) É uma questão mesmo pessoal. A gente deu todo suporte dele, tal. A empresa dele lá, que era... que ele fazia parte, num tava dano suporte. Eu cheguei pra o meu gerente, a gente falô "Não, vamo... vamo dá todo suporte que ele precisa!" (JLS Corpus PCVC)

\footnotetext{
5 Usamos, na presente pesquisa, o termo real como sinônimo de concreto.
} 
v. 7 (2)

74-92

ago/dez 2017
Nos dois exemplos, ocorre uma transferência metafórica. Em (1) temos $\left[\mathrm{X}_{\text {(uma pessoa) }}+\mathrm{DAR}_{\text {(informação) }}+\mathrm{Y}_{\text {(gente) }}\right]$, no qual uma pessoa transfere intencionalmente informações para outra. O destinatário, por sua vez, passa a possuir essas informações, ou seja, é afetado pela mudança da ação. Em (2) $\left[\mathrm{X}_{\text {(nós) }}+\mathrm{DAR}_{\text {(suporte) }}+\mathrm{Y}_{\text {(ele) }}\right]$, o informante pretende ajudar o funcionário, para isso ele fornecerá o suporte necessário. Assim como no primeiro exemplo, o que será transferido possui uma natureza abstrata, há intencionalidade na ação, e o paciente é afetado, o funcionário terá a ajuda que precisa. O sentido fornecer, utilizado aqui, localiza-se mais próximo do sentido base do verbo dar no processo de gramaticalização, pois conserva a noção de transferência, mesmo que metafórica.

Além da extensão fornecer, o sentido ensinar foi muito utilizado por informantes que são professores. Esse fato explica porque essa extensão de sentido apareceu de forma mais produtiva no Corpus do Português Culto. Dessa forma, de acordo com o exemplo (3), temos $\left[\mathrm{X}_{(\mathrm{eu})}+\mathrm{DAR}_{\text {(treinamento) }}+\mathrm{Y}_{(\text {(ele) }}\right]$.

(3) Quando ele tá sob risco, eu falo "não, tá dessa forma". Dô um treinamento, passo uma palestra, que eu vejo que ele se conscientiza, eu me sinto importante naquela hora. (JLS Corpus PCVC)

Entendemos que essa ação também constitui uma transferência metafórica, pois o informante é o responsável pela transferência intencional de informação. No entanto, a ação não está concluída. Além disso, o possuidor do treinamento não está explícito na ocorrência, mas, pelo contexto, podemos considerar que se trata do funcionário do informante, por isso, o nível de transferência deve ser considerado mais baixo em comparação ao sentido fornecer.

A terceira extensão, com sentido bater, expressa nos corpora uma intenção agressiva:

(4) O professô escrevia um bilhetinho e mandava e ele tinha que entregá [ao] pai aquele bilhetinho, e de lá da casa do pai, o pai recebia aquele bilhetinho, chegava lá, além de ele tê levado uma dúzia de bolo na sala lá [do] que o professô dava, o professô tinha autoridade pra fazê isso... dava uma dúzia de bolo e chegava em casa que ele recebia o bilhetinho, pai dava ôta surra, ôta disciplina nele. (DAO Corpus PCVC) 
No exemplo (4), temos dois agentes, o professor e o pai, que agiram intencionalmente, de forma agressiva, podemos dizer, em relação ao aluno/filho. O destinatário é, então, afetado pela ação. O verbo dar, dessa forma, indica que o menino levou uma surra do professor e do pai. Dar uma dúzia de bolo ou dar uma surra veicula um evento concluído, o que indica um alto nível de transitividade, de acordo com os parâmetros propostos por Hopper e Thompson (1980).

Além dessas acepções, o dar também é abordado com o sentido de gerar/produzir. Verifiquemos em (5) e (6)

(5) Olha só, a mídia hoje em dia... ela prioriza mais o lado da violência, infelizmente. Você liga a TV, você vê lá muita coisa só notícia ruim, infelizmente, muita violência muita agressão física... muita morte... e... o que é pior todos os canais de televisão cobre isso, né, não sei por que, não sei se é por que dá muita audiência... não sei se... num é possível que as pessoas gostam de ver e ouvir esse tipo de coisa, é lamentável, né. (RFV Corpus PCVC)

(6) Espero em Deus que um dia eu consigo, um dia eu vou dizer "consegui, consegui ser aquela... aquela plantinha que... aquela sementinha que caiu na terra boa e produziu e deu frutos à vontade" vou dar! (JLS Corpus PCVC)

Em (5) $\left[\mathrm{X}_{\text {(notícia ruim) }}+\mathrm{DAR}_{\text {(audiência) }}\right]$, não existe um destinatário afetado, nesse sentido, o evento não produz uma situação com intencionalidade ou uma ação concluída. As notícias produzem maior audiência para a televisão. Se pensarmos no nível de gramaticalização, esse exemplo se assemelha à categoria de verbo suporte. No exemplo (6) $\left[\mathrm{X}+\operatorname{Dar}_{(\text {frutos) }}\right]$, a informante demonstra perceber a extensão de sentido do dar, já que faz uso do verbo produzir. Nesse caso, há a intenção de transferir, mas não existe um destinatário, e o que será transferido não está claro no contexto. Além disso, o evento não possui um tempo determinado; por isso, essas razões levam a uma baixa transitividade.

O sentido gerar/produzir, por apresentar baixo nível de transferência, aproxima-se, então, de categorias mais afastadas do sentido pleno do verbo dar. A noção de causa, por sua vez, também pode ser enquadrada na categoria de verbo suporte. Ao tratar do verbo causativo, Rassi e Vale (2013) afirmam que o verbo dar, nesses casos, 
v. 7 (2)

74-92

ago/dez 2017

pode indicar uma causa provocada por um argumento, o que é o caso de (a) o exercício físico dá sede em Ana, ou indicar uma atribuição, em que o agente atribui alguma característica ao objeto, como em (b) Zé deu transparência ao processo. (RASSI; VALE, 2013, p.115-116). A ocorrência (7) encontrada nos corpora se assemelha ao exemplo (a) das autoras, pois o verbo dar possui o conteúdo semântico de causa.

(7) Mas é preferível a família sentá pra conversa do que vê a tragédia lá na televisão que só vai dá angústia só... só vai dá medo, então, na hora que cê tá almoçando, você nem vai conseguir digerir essa comida magine aquel' sofrimento, então a gente sab' que in... infelizmente tem. (JVB Corpus PCVC)

No exemplo (7) $\left[\mathrm{X}_{\text {(televisão) }}+\mathrm{V}_{\text {(causativo) }}+\mathrm{Y}_{\text {(quem assiste) }}\right]$, a predicação é um sentimento, ele não é gerado intencionalmente, mas afeta a informante. Assistir à tragédia na televisão transmite angústia e medo para quem está assistindo. Esse evento não possui um término ou um agente humano, mas o contexto indica a certeza de que a ação ocorrerá. O verbo dar, nesse caso, portanto, possui o sentido de causa. A tragédia, portanto, causa angústia e medo.

Temos, na ocorrência (8), o verbo dar com o sentido de combinar/ entender em três momentos. Nesse exemplo, não há como avaliar os parâmetros propostos por Hopper e Thompson (1980).

(8) Eu dô bem com todo mundo, graças a Deus. [...] eu gosto do frio, num gosto muito é do calô, que eu num dô bem com o calô. (CDS Corpus PPVC)

O verbo dar é usado como uma expressão construída por uma sequência relativamente fixa na língua. A informante usa a expressão $\left[\mathrm{P}_{(\mathrm{eu})}+\mathrm{V}_{\text {(dar) }}+\right.$ bem] eu dô bem para dizer que consegue se relacionar de forma adequada com todo mundo e que não consegue se adequar à temperatura quente. O dar, novamente, perde o seu valor semântico básico para possuir, então, uma extensão semântica, próxima ao verbo sentir.

A extensão de sentido soar, assim como as acepções produzir/ gerar, causar e combinar/entender, está em um processo mais avançado de gramaticalização. Observemos: 
(9) Quando é frio, é bem frio, frio honesto, frio que dá duas horas assim a gente está congelando, é... e depois tem verão, faz calô, Conquista tem um clima maravilhoso, rapaz, muito bom! (AIRM Corpus PCVC)

Alguns lexicógrafos, como Houaiss et al (2009) e Ferreira (2010), afirmam que, nesse tipo de ocorrência, o dar substitui o verbo soar, que indica horas ou algum horário específico. Atualmente, o verbo soar é pouco utilizado na língua falada, por isso podemos afirmar que o verbo dar está se cristalizando nesse tipo de estrutura. Com relação aos parâmetros analisados, o evento é concluído, pois há uma mudança no clima devido ao horário.

Em casos em que o verbo dar passa a significar possibilidade, também não é possível identificar os parâmetros propostos por Hopper e Thompson (1980). As ocorrências (10) e (11) exemplificam isso:

(10) Tem aquela questão financeira que você sabe que... não é... não é tão atrativa assim você participar mais... se fosse o último caso... dá pra... dá pra manter pelo menos os estudos, né, que é claro o objetivo é desse de... da pessoa ta ali é... estudando e... engajado no... no projeto pra... sustentá nos estudos. (RFV Corpus PCVC)

(11) DOC: E a renda dele é boa, assim, que dá pra sustentar a família? INF: Dá pa sustentar... dá pa levar... a renda dele dá pa sustentar. (CDS Corpus PPVC)

Aqui, percebemos uma extensão de sentido do verbo dar, visto que ele indica possibilidade. Poderia ser dito, então, é possível manter pelo menos os estudos, no exemplo (10); ou é possivel sustentar no exemplo (11). O dar, portanto, não expressa transitividade, então notamos que esse item passa a ter sentidos distintos ao passo que o processo de gramaticalização aumenta. Essa extensão de sentido segue uma estrutura fixa na língua, em que $\left[\mathrm{V}_{(\text {dar }}+\mathrm{pra} / \mathrm{pa}+\mathrm{V}_{\text {(infinitivo) }}\right]$, como se apresenta nos exemplos (10) e (11).

Nesta subseção, elencamos as extensões de sentido do verbo dar de acordo com o processo de gramaticalização de cada caso. O dar, então, de acordo com as ocorrências encontradas nos corpora, possui nove extensões de sentido, como mostra a fig. 1: 
v. 7 (2)

74-92

ago/dez

2017

Figura 1 - Extensões de sentido do verbo dar

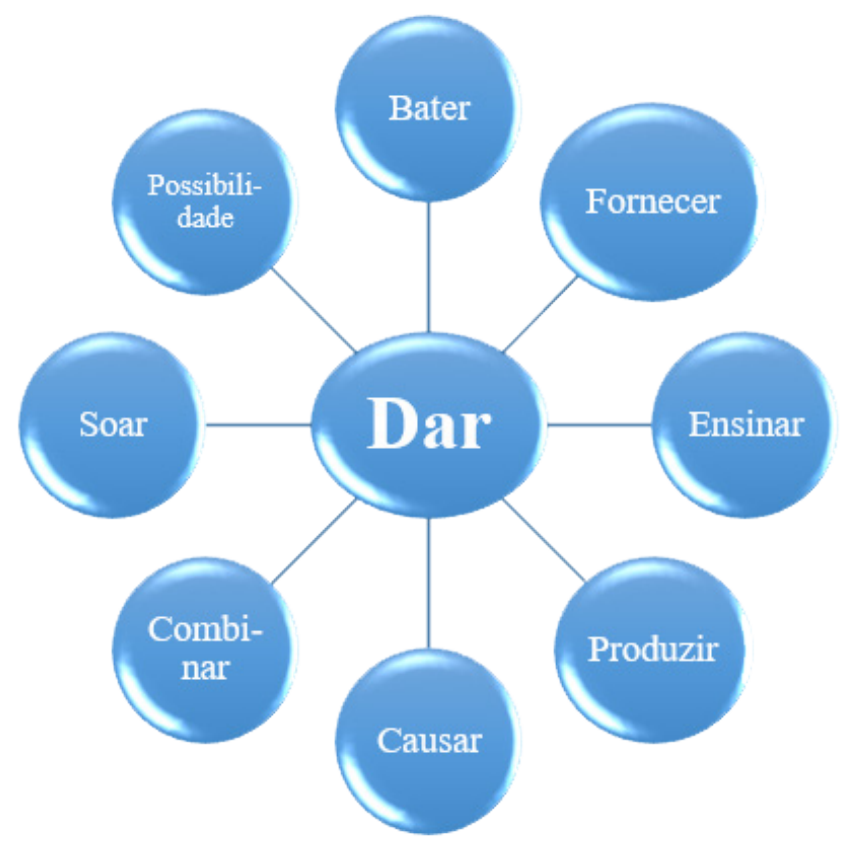

Iniciamos por fornecer, ensinar, bater e produzir, pois acreditamos que esses verbos conservam a ideia de transferência, variando apenas o grau de abstração de cada ocorrência. Causar, combinar, soar e possibilidade, no processo de gramaticalização, localizam-se mais afastados da noção de transferência, na medida em que envolvem outras ações. Maciel (2005), ao estudar os sentidos de construções lexicais complexas constituídas com o verbo dar (CLCDs), afirma que

[...] pode-se constatar que o sentido da construção central DOAÇÃO é irradiado para outros sentidos, de forma total, como por exemplo, na CLCDs 'dar carinho' ou de forma parcial, como ocorre na CLCDs 'dar vontade' ou é totalmente apagada como ocorre em construções 'dar por água abaixo'. (MACIEL, 2005, p. 112)

O autor ainda assevera que, por meio das metáforas irradiadas do verbo dar, podemos perceber que as expressões "formam um mecanismo sistemático para expressar os diversos aspectos do ato de doar intrínseco ao homem" (MACIEL, 2005, p. 119). Esteves (2008) também descreve as extensões de sentido do verbo dar. Em sua pesquisa, o dar possui oito acepções distintas, são elas: fornecer, atribuir, ensinar, produzir, causar, bater, ocorrer e ter. Algumas dessas acepções foram empregadas pelos informantes nos corpora investigados por nós, no entanto, a extensão de sentido bater, para Esteves (2008, p.119), indica horas, como no exemplo quando deu a hora de nós irmos para a escola [...]. 
Em termos linguísticos, podemos afirmar que o uso do verbo dar em seus respectivos sentidos sofre variação por parte do informante que, a depender do contexto ou da situação de uso, manipula o verbo e atribui-lhe a expressividade desejada e necessária ao ato interativo. Ao lado disso, em termos sociolinguísticos, podemos, ainda, averiguar que o uso do verbo dar em seus múltiplos sentidos, nas mãos do informante, sofre variação de acordo, sobretudo, com a variável social nível de escolarização. Observemos os resultados conforme o Corpus do PPVC e o Corpus do PCVC:

Gráfico 1 - Extensões de sentido do verbo dar utilizadas pelos informantes dos corpora

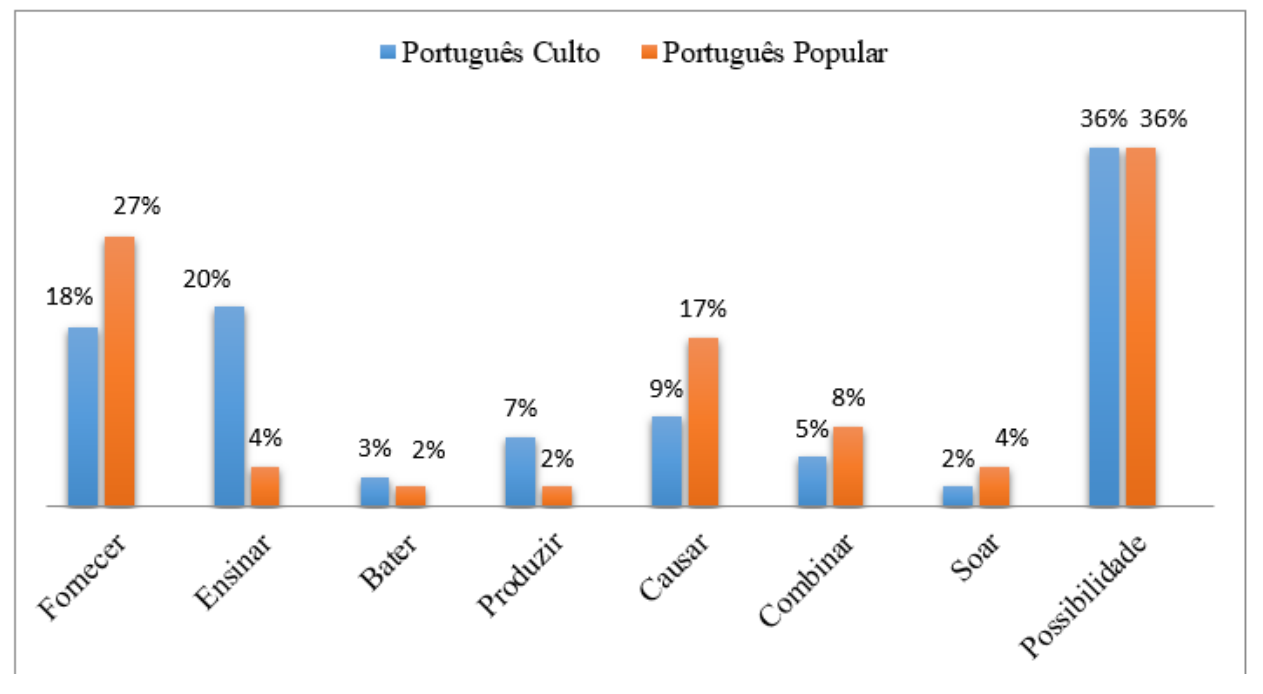

A extensão de sentido mais produtiva em nosso corpora, independente do grau de escolaridade, foi dar é possibilidade. Esse sentido apareceu em 39 ocorrências e em um percentual semelhante de $36 \%$ em ambos os corpora. De igual forma, a extensão de sentido menos produtiva foi dar é bater, que apareceu 3\% e $2 \%$ nos corpora PCVC e PPVC, respectivamente.

O sentido dar é ensinar, como já havíamos observado, está mais presente no vernáculo culto dos conquistenses. Em função disso, há, em nossos dados, uma diferença percentual significativa de $20 \%$ no Corpus PCVC versus 4\% no Corpus PPVC. Em uma proporção inversa, registrando 17\% no Corpus PCVC e 9\% no Corpus PPVC está o verbo dar como causar.

As demais extensões semânticas do verbo dar, como dar éproduzir, dar é combinar e dar é soar, aparecem com pequenos percentuais de diferença, sinalizando, a nosso ver, apenas que determinado uso, vez por outra, é mais recorrente em determinado vernáculo. 
v. $7(2)$

74-92

ago/dez 2017

Dar como fornecer foi empregado 24 vezes no total, isto é, em $22 \%$ das ocorrências, enquanto o sentido mais gramaticalizado do verbo, dar é possibilidade, apareceu em 39 ocorrências, totalizando 36\%. O informante, ao utilizar as extensões de sentido do verbo dar no lugar de um verbo pleno correspondente, demonstra que o acesso a alguns conhecimentos possibilita que o falante tenha mais opções semânticas para se expressar.

\section{Considerações finais}

A presente pesquisa nos permitiu dialogar com estudos já realizados sobre o verbo dar, bem como descrever e analisar a extensão semântica desse verbo novernáculo conquistense. Àluz do Funcionalismo norteamericano, compreendemos que velhas formas passam a ocupar novos sentidos diante de uma necessidade na interlocução, assim, o informante, a depender da situação de uso, manipula o verbo para aplicar a expressividade desejada ao ato interativo.

Constatamos que o verbo dar, apesar do processo de gramaticalização, conserva, mesmo que em partes, o seu valor semântico de transferência, passando, muitas vezes, a possuir o valor de transferência metafórica, o que provocaria uma discussão sobre o princípio de persistência, postulado por Hopper (1980). Ademais, verificamos que as acepções produtivas do verbo dar nos corpora investigados foram: fornecer, ensinar, bater, produzir, causar, combinar, soar e possibilidade. Mostramos que as quatro primeiras extensões estão mais próximas do sentido pleno do verbo dar, pois conservam a noção de transferência, mesmo que metafórica. E, por outro lado, os sentidos causar, combinar, soar e possibilidade envolvem outras ações, portanto, localizam-se mais afastados do valor de transferência.

Por fim, ressaltamos que o estudo do processo de gramaticalização do verbo dar não se esgota nesta pesquisa, ainda há muito o que pesquisar sobre a configuração semântica de construções com o dar. Demos, apenas, um passo.

\section{Referências}

BYBEE, Joan. Língua, uso e cognição. Tradução de Maria Angélica Furtado da Cunha e revisão técnica de Sebastião Carlos Leite Gonçalves. São Paulo: Cortez, 2016.

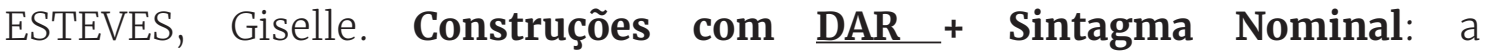


gramaticalização desse verbo e a alternância entre perífrases verbo-nominais e predicadores simples. Giselle Aparecida Toledo Esteves. Rio de Janeiro: UFRJ/ FL, 2008.

FERRARI, Lilian. Introdução à linguística cognitiva. São Paulo: Contexto, 2016.

FERREIRA, Aurélio Buarque de Holanda. Dicionário Aurélio da Língua Portuguesa. Coordenação Marina Baird Ferreira e Margarida dos Anjos. 5. Ed. Curitiba: Positivo, 2010.

GIVÓN, Talmy. Functionalism an Grammar. Amsterdam/Philadelphia: John Benjamins, 1995.

HEINE, Bernd; CLAUDI, Ulrike; HUNNEMEYER, Frederike. Grammaticalization: aconceptual framework. Chicago: The University of Chicago Press, 1991.

HOPPER, P; THOMPSON, S. A transitivity in grammar and discourse. Language, V. 56, 1980.

HOPPER, Paul; TRAUGOTT, Elizabeth. Grammaticalization. Cambridge: CUP, 1993.

HOUAISS, Antônio; VILLAR, Moura de Sales. Dicionário Houaiss da língua portuguesa. Rio de Janeiro: Editora Objetiva, 2009.

LAKOFF, George; JOHNSON, Mark. Metáforas da vida cotidiana. Tradução do Grupo de Estudos da Indeterminação e da Metáfora, coordenado por Mara Sophia Zanotto e Vera Maluf. Campinas (SP): Mercado de Letras; São Paulo: EDUC, 2002.

MACIEL, João Wandemberg G. Construções lexicais complexas constituídas com o verbo dar: processos metafóricos de construção de sentidos. Tese (Doutorado) - UFPB/BC, João Pessoa, 2005.

MARTELOTTA, Mario E.; AREAS, Eduardo K. A visão funcionalista da linguagem no século XX. In: CUNHA, Maria A. Furtado da; OLIVEIRA, Mariângela Rios; MARTELOTTA, Mario E. (org.). Linguística funcional: teoria e prática. Rio de Janeiro: DO\&A, 2003.

MARTELOTTA, Mario E.; VOTRE, Sebastião J.; CEZARIO, Maria M. O paradigma da gramaticalização. In: MARTELOTTA, Mario E.; VOTRE, Sebastião J.; CEZARIO, Maria M. Gramaticalização no português do Brasil. Rio de Janeiro: Tempo Brasileiro, 1996.

MARTELOTTA, Mário Eduardo (Org.) Manual de linguística. São Paulo: Editora Contexto, 2008.

MEILLET, Antoine. Linguistique historique etlinguistique générale. Paris: Libraire Ancienne Honoré Champion, 1965.

NEVES. M. H. M. Estudo das construções com verbo suporte em português. In: $\mathrm{KOCH}$, Ingedore Villaça (Org.) Gramática do português falado. V. VI: Desenvolvimentos. Campinas, SP: Editora da Unicamp, 1996. 
v. 7 (2) 74-92 ago/dez 2017

NEVES, M. H. M. Texto e Gramática. São Paulo: Contexto, 2006.

RASSI. Amanda P.; VALE. Oto A. Tipologia das construções verbais em português do Brasil: uma proposta de classificação do verbo dar. Caligrama, Belo horizonte, v. 18, n.2, p. 105-130, 2013.

SALOMÃO, M. M. M. Polysemy. Aspect and modality in Brasilian Portuguese. The case for a cognitive explanation of grammar. Tese de doutorado. University of California at Berkeley, 1990.

SAUSSURE, Ferdinand de. Curso de Linguística Geral. 34. ed. São Paulo: Cultrix, 2012.

Recebido em: 13 de fev. de 2017. Aceito em: 13 de jul. de 2017. 